\title{
USE OF PAPER PATCHING AND TINCTURE FERRI PERCHLORIDE FOR DAY CARE MANAGEMENT OF TYMPANIC MEMBRANE PERFORATION
}

\begin{tabular}{ll}
\hline ENT & \\
$\begin{array}{l}\text { Dr. Raj Rajendra } \\
\text { Singh Seth }\end{array}$ & $\begin{array}{l}\text { Professor And Head, Department Of ENT, Career Institute Of Medical Sciences, } \\
\text { Lucknow (UP) India. }\end{array}$ \\
\hline $\begin{array}{l}\text { Dr. Shivesh } \\
\text { Kumar* }\end{array}$ & $\begin{array}{l}\text { Assistant Professor, Department Of ENT, Career Institute Of Medical Sciences, Lucknow } \\
\text { (UP) India. * Corresponding Author }\end{array}$ \\
\hline $\begin{array}{l}\text { Dr. Amit Kumar } \\
\text { Rana }\end{array}$ & $\begin{array}{l}\text { Assistant Professor, Department Of Otorhinolaryngology And Head Neck Surgery, } \\
\text { SRMS Institute OfMedical Sciences, Bareilly (UP), India. }\end{array}$ \\
\hline
\end{tabular}

\section{ABSTRACT}

INTRODUCTION: Perforation of tympanic membrane constitutes a major portion of patients attending ENT OPD for which they are advised surgical procedures. Most of the cases with small perforations can be managed by doing OPD procedure of cautery patching and hence surgical procedure can be avoided.

METHODS: The study was conducted in the tertiary hospital from August 2018 to July 2019. The patients were selected on the basis of the inclusion criteria after doing clinical examination, and audiometry. All the patients underwent cautery patching with tincture ferri perchloride and patch placed. The patients were followed up weekly till the perforation was completely closed or uptill 3 months.

RESULTS: Total of 65 patients was included in the study. Most common etiology of perforation was inflammatory involving anteroinferior quadrant as most common etiology with success achieved in 56 patients.

CONCLUSION: patients with small central dry perforation of tympanic membrane, cautery patching using tincture ferri per chloride and paper patching gives good results comparing to the surgical procedure, while ablating the morbidity and psychological trauma of the surgery.

\section{KEYWORDS}

\section{Tympanic Membrane, Chemical Cautery, Tincture Ferri Per Chloride, Paper Patching}

\section{INTRODUCTION:}

Perforation of tympanic membrane is very common otology condition for which patient seeks medical attention. Perforation with long history usually leads to hearing loss, pain in ear, heaviness in ear, recurrent discharge. For this reason the closure of perforation of tympanic membrane is required to restore and to improve hearing of the patients and to reduce complaints of heaviness. Moreover aspirant young boy opting jobs in army who have been temporarily made misfit, come to ENT OPD with request of closure of tympanic membrane perforation, In such case an incision for repair and its scar closes the entry door to forces making permanent disability to air force (active $)^{(3,5)}$. It is OPD procedure so there is no issue of missing work or taking leave from office or studies.

For surgical approach microscope and nowadays endoscopes plays a very important role. Many patients usually don't want to undergo surgical procedure either because of the surgical cost or fear for the surgery, and its failure anticipated by them ${ }^{1}$. Even with all aseptic conditions and nicely done surgery there is a chance of failure of the surgery which results in residual perforation.

Because of these issues, patching of tympanic membrane is becoming popular in perforations which are smaller in size and can be managed in OPD with least complications. There is no incision scar and the tympanic membrane which when heals is a natural tympanic membrane of the patient and not a repaired one of graft tissue making it the ideal case for entry in armed forces. Success of this procedure is quite high if selection of case is correct, and if patients come timely for review. Patients not proper for such repair are subjected to routine operative procedures

\section{MATERIALAND METHODS:}

This study has been conducted on 65 patients attending OPD of Otorhinolaryngology and Head and Neck Surgery of a tertiary care hospital in Uttar Pradesh, India. A detailed history and examination was done to rule out any other generalized disease related to ENT, although for such procedure no disease is a contraindication.

Inclusion criteria:

- Dry Ear having central perforation, of small or medium size (less than $4 \mathrm{~mm}$ )

- Conductive deafness

- AOM perforation after infection subsides.

- Unhealed small traumatic perforation

\section{Exclusion criteria:}

- Subtotal perforation or marginal perforation

- Squamosal Disease

- Pulsatile discharge

- Granulations in middle ear

- Profusely discharging ear

- Sensorineural hearing loss

- Tympanosclerotic membrane

- Previous ear surgery

After considering the above criteria of selecting the patient, detailed history was taken and examination was done with help of Welch Allyn Otoscope and oto-endoscopy was done to confirm the findings. Dry ear for at least 2 weeks was ideal perquisite for repair. Pure tone audiometry (PTA) was done after explaining the procedure to the patient in the audiometry room and their audiogram were recorded and kept for post procedure comparing

Any debris or wax if present in the External auditory canal (EAC) was cleaned. 4\% Xylocaine cotton ball was placed in EAC for anesthesia of EAC and tympanic membrane. After viewing with zero degree endoscope the perforation margin is freshened with help of chemical cauterization with Tincture ferri perchloride, making sure that minimum $1 \mathrm{~mm}$ of margin gets raw. After this small pieces of abgel are placed in the middle ear. Small piece of cigarette filter paper soaked in betadine is placed over the perforation with the help of applicator and micro cup forceps as a support for the epithelization of the tympanic membrane. Betadine is used for the local disinfection and helps the filter paper to stick and stay. Patient is advised to avoid ear cleaning, water entry or any local ear drop, to report if catches cold and not to blow nose. Patients are followed up after 1 week to check for the position of filter paper in case of any patch displaced it was replaced readjusted over the perforation. Patient is again followed up at a regular interval of 2 weeks. If tympanic membrane growth is not observed then patient was advised surgery, but if growth occurs and size of perforation is reduced, a second repair is done in the same way.

\section{OBSERVATIONS AND RESULTS}

A total of 65 patients were taken in the study out of which 28 were male patients and 37 were female (Table1). Age of the patients was between 16 to 56 years (Table 2). Etiology suggested that 47 patients had infective pathology and 11 cases were traumatic due to ear cleaning, accident or slap injury. Rest 07 cases no definite (Table 3) cause could be ascertained as they were old cases of discharging ear. Most common 
size of perforation was 1-2mm in size (Table 4) and the most common area involved was anteroinferior quadrant (Table 5). Success in closing the perforation was present in 56 cases (Table 6) and in 09 the procedure was unsuccessful, and such patients were advised surgery. Post treatment hearing improvement was present in 52 patients shown by closure ofAB Gap (Table 7).

TABLE 1: SEX DISTRIBUTION:

\begin{tabular}{|l|l|l|}
\hline SEX & NO. OF PATIENTS & PERCENTAGE \% \\
\hline Male & 28 & 43.07 \\
\hline female & 37 & 56.92 \\
\hline
\end{tabular}

TABLE 2: AGE DISTRIBUTION

\begin{tabular}{|l|l|l|}
\hline AGE(IN YEARS) & NUMBER OF PATIENTS & PERCENTAGE \% \\
\hline 16-26
\end{tabular}

\begin{tabular}{|l|l|l|}
\hline $\mathbf{1 6 - 2 6}$ & 08 & 12.3 \\
\hline $\mathbf{2 7 - 3 6}$ & 27 & 41.53 \\
\hline $\mathbf{3 7 - 4 6}$ & 24 & 36.92 \\
\hline $\mathbf{4 7 - 5 6}$ & 06 & 10.83 \\
\hline
\end{tabular}

TABLE 3: ETIOLOGY OF PERFORATION:

\begin{tabular}{|l|l|l|}
\hline ETIOLOGY & NUMBER OF PATIENTS & PERCENTAGE \% \\
\hline
\end{tabular}

\begin{tabular}{|l|l|l|}
\hline INFLAMMATORY & 47 & 72.30 \\
\hline TRAUMATIC & 11 & 16.92 \\
\hline UNKNOWN & 07 & 10.76 \\
\hline
\end{tabular}

TABLE 4: SIZE OF PERFORATION

\begin{tabular}{|l|l|}
\hline SIZE OF PERFORATION & NUMBER OF PATIENTS \\
\hline LESS THEN 1 MM & $15(23.07 \%)$ \\
\hline 1-2MM & $29(44.61 \%)$ \\
\hline 3-4MM & $21(32.30 \%)$ \\
\hline
\end{tabular}

TABLE 5: SITE OF PERFORATION:

\begin{tabular}{|l|l|l|}
\hline $\begin{array}{l}\text { QUADRANT } \\
\text { INVOLVED }\end{array}$ & $\begin{array}{l}\text { NUMBER OF } \\
\text { PATIENTS }\end{array}$ & PERCENTAGE \% \\
\hline ANTEROSUPERIOR & 08 & 12.30 \\
\hline ANTEROINFERIOR & 24 & 36.92 \\
\hline POSTEROSUPERIOR & 20 & 30.76 \\
\hline POSTEROINFERIOR & 13 & 20.0 \\
\hline
\end{tabular}

TABLE 6: COMAPRISON OF SIZE OF PERFORATION WITH PROCEDURE OUTCOME:

\begin{tabular}{|l|l|l|l|}
\hline $\begin{array}{l}\text { SIZE OF } \\
\text { PERFORATION }\end{array}$ & $\begin{array}{l}\text { NUMBER OF } \\
\text { PATIENTS }\end{array}$ & $\begin{array}{l}\text { HEALED } \\
\text { PERFOATION }\end{array}$ & $\begin{array}{l}\text { UNHEALED } \\
\text { PERFORATION }\end{array}$ \\
\hline $\begin{array}{l}\text { LESS THEN 1 } \\
\text { MM }\end{array}$ & $15(23.07 \%)$ & $14(93.33 \%)$ & $01(7.14 \%)$ \\
\hline $\mathbf{1 - 2 M M}$ & $29(44.61 \%)$ & $27(93.10 \%)$ & $02(7.40 \%)$ \\
\hline 3-4MM & $21(32.30 \%)$ & $16(76.19 \%)$ & $05(31.25 \%)$ \\
\hline TOTAL & $65(100.00 \%)$ & $56(86.15 \%)$ & $09(13.84 \%)$ \\
\hline
\end{tabular}

TABLE 7: AUDIOMETRIC RESULT COMPARISION AT 3 MONTH FOLLOW UPWITH PRE OPERATIVE VALUES:

\begin{tabular}{|l|l|l|l|l|}
\hline AB GAP & $\begin{array}{l}\text { PRE- } \\
\text { TREATMENT } \\
\text { PATIENTS }\end{array}$ & $\begin{array}{l}\text { PERCENTA } \\
\text { GE } \%\end{array}$ & $\begin{array}{l}\text { POST- } \\
\text { TREATME } \\
\text { NT } \\
\text { PATIENTS }\end{array}$ & $\begin{array}{l}\text { PERCENT } \\
\text { AGE \% }\end{array}$ \\
\hline $\mathbf{1 0}$ & 09 & 13.84 & 29 & 44.61 \\
\hline $\mathbf{1 1 - 2 0}$ & 24 & 36.92 & 15 & 23.07 \\
\hline $\mathbf{2 1 - 2 0}$ & 17 & 25.75 & 12 & 18.46 \\
\hline $\mathbf{3 1 - 4 0}$ & 09 & 13.84 & 06 & 9.23 \\
\hline $\mathbf{4 1 - 5 0}$ & 04 & 6.15 & 02 & 3.07 \\
\hline $\mathbf{> 5 0}$ & 02 & 3.07 & 00 & 00 \\
\hline TOTAL & 65 & 100.00 & 65 & 100.00 \\
\hline
\end{tabular}

\section{DISCUSSION:}

In long standing perforations of tympanic membrane there occurs a squamous epithelial growth, which curves around the perforation edge inwards thus giving an epithelial lined perforation margin through which the healing of tympanic membrane perforation does not occur ${ }^{2}$. These perforations thus need freshening of margins or chemical cauterization, happens as with any non- healing wound mentioned as undermining skin edge ${ }^{7}$. Due to such natural healing process antibiotic drops are not prescribed, no other drop or water entry is allowed because it passes through perforation; and damages the epithelial lining and delays the "perforation-healing".
Sellar S.L in one study did 9 times cautery patching for the closure of perforation ${ }^{6}$, while Derlacki did 64 attempts for the final closure of perforation in one of his case series of 129 cases

Our studies compares well with the other methods used in the past for the closure of tympanic membrane perforation, the epithelial lining of tympanic membrane has potency to grow and this causes certain pin point perforation (usually traumatic) to heal spontaneous, but when antibiotic-steroid ear drops are used then edge heals and this makes the perforation non healing. We freshened the margin by chemical cautery which allows spontaneous growth of epithelium over the support provided by abgel below in the middle ear and cigarette paper above the perforation margin. Our success rate with this technique is almost $86 \%$ percent. The procedure includes only local anesthesia of the canal with $4 \%$ Xylocaine and freshening up of the margins. The average duration for the spontaneous closure of the perforation is from 2-3 months. We don't use any ear drops after the procedure and don't allow ear cleaning by patient and ask patient to avoid water entry in ear by plugging ear by dry oil soaked cotton for 2-3 months. Pre operative and post operative audiograms kept for assessment of improvement.

The use of trichloro acetic acid (TCA) or Silver nitrate has reports of injury to middle ear causing necrotizing otitis media, hearing loss, facial paralysis ${ }^{4}$, which is not occurred and is avoided by our procedure. The success rate with our procedure is almost $86 \%$, similar percentages of success are also been reported by various authors in the past. We have not used this procedure in the age below 16 years or over 56 years so no conclusion can be made regarding the use of patching in this age. By performing this procedure in the perforated tympanic membrane we have managed to decrease the waiting list of surgery and expense of the patients.

\section{CONCLUSIONS:}

With proper selection of the patients having small to medium size perforation, this procedure gives good results by using chemical cauterization with abgel and cigarette filter paper patch and can overcome the surgical procedure. Multiple visits are required by the patients but is very safe and more over it can be performed as OPD procedure and patients can continue his daily work without with no need of hospital stay. It requires very simple instruments, so can be done in periphery or small centers where sophisticated equipment's are not available.

\section{REFERENCES:}

1. Upreti G.Office myringoplasty by chemical cauterization and paper patching: prospective study Int J Otorhinolaryngol Head and Neck Surg. 2019 Jan; 5(1):55-59

2. Ganesh Bala, Kannappan A.L, Nahas T.K,Arun Khosh. Chemical cauterization by using Trichloroacetic acid in tympanic membrane perforation:Our experience.J of Evolution Med.Dent.Sci/eISSN-2278-4802,pISSN2278-4748/Vol.05/Issue34/Apr.28,2016.

3. M.Singh, M Kaur, B Singh, K Singh, A Singh, A kaur. Role of Trichloroacetic acid and gelfoam in closure of tympanic membrane perforations.Nijer J Clin Pract 2017;20:1233-6.

4. Vikramjit Singh Parmar, T.L.Parmar, Gopal Singhal, poonam Pathania. Chemical cauterization of tympanic membrane perforations. J of Evolution Med.Dent.Sci/eISSN2278-4802,pISSN2278-4748/Vol.04/Issue32/Apr.20,2015.

5. Sellar S.L(1996) Closure of tympanic membrane perforation by cautery reappraisal,Journal of laryngology,83:487.

Derlecki EL(1953) repair of central perforation of tympanic membrane,Arch Otolaryngeal 8,405 .

7. T.Santhi, K.V.Rajan. A study of closure of tympanic membrane perforations by chemica cauterization. Indian J Otolaryngol Head Neck Surg.(October-December 2012) 64(4):389-392.

8. Gulya AJ, Glasscock ME (2003), Shambaugh surgery of the ear,5th edn. BC Decker Inc, Spain,pp 400-420. 